\title{
A 73 Years Old Man with Necrotizing Pneumonia and chronic Obstructive Pulmonary Disease
}

Rahmetulla Iri ${ }^{1}$, Sabah Hassani $^{* 2}$

1. Medical Student, Student Research Committee, Kurdistan University of Medical Sciences, Sanandaj, Iran, ORCID ID: 0000-0001-6068-7922

2. Assistant Professor, Internal Medicine Department, Medicine Faculty, Kurdistan University of Kurdistan, Sanandaj, Iran., (Corresponding Author ), Tell: 08733286112, E-mail: s.hasani@muk.ac.ir, ORCID ID: 0000-0002-1165-5040.

\begin{abstract}
Background and Aim: Necrotizing pneumonia is an uncommon disorder with a high mortality rate. Different factors are involved in the incidence of this disease.

Case: A 73 years old man was admitted to the hospital with a chief complaint of dyspnea and productive cough. Chest x-ray showed a consolidation in the lower lobe of the left lung and a CT-scan revealed a cavity in the lingula. Bronchoscopy was performed and examination of bronchoalveolar lavage (BAL) fluid was positive for acid-fast bacilli. Anti-tuberculosis drugs were started for the patient.

Conclusion: Our case demonstrates a rare manifestation of tuberculosis associated with lung necrosis and cavitation, which emphasizes the necessity of examination and work-ups for mycobacterium TB in patients with drug resistant chronic pulmonary disease.

Keywords: Mycobacterium tuberculosis, COPD, Necrotizing pneumonia

Received: Dec 1, $2018 \quad$ Accepted: July 7, 2019

How to cite the article: Rahmetulla Iri, Sabah Hassani. A 73 Years Old Man with Necrotizing Pneumonia and chronic Obstructive Pulmonary Disease. SJKU. 2020;25(5):141-146.

Copyright (C) 2018 the Author (s). Published by Kurdistan University of Medical Sciences. This is an open access article distributed under the terms of the Creative Commons Attribution-Non Commercial License 4.0 (CCBYNC), where it is permissible to download, share, remix, transform, and buildup the work provided it is properly cited. The work cannot be used commercially without permission from the journal
\end{abstract}




\section{ينومونى نكروزان و بيمارى مزمن انسدادى ريه در يك مرد VT ساله}

رحمتالله ايرى'، صباح حسنى

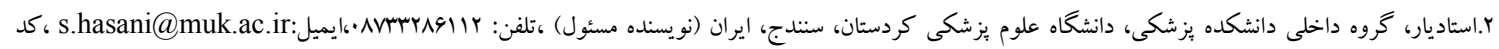

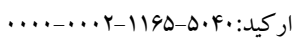

حكيuه زمينه و هدف: ينومونى نكروزان يكى از بيمارىهاى ناشايع ريوى است كه درصد مركّومير بالايى دارد، عوامل مختلى مىتواند در بروز اين بيمارى دخيل باشند. مورد: بيمار آقاى V^ ساله با سرفه و تنكى نفس كه طى بررسىهـاى انجـامشـده توسط تصـويربردارى Xray و سـىتى اسـكن و برونكوسكويى از ريه بيمار نمونه گرفته شد ـ در بررسى صـورت گرفته از لاواز توسط تسـت اسـيد فسـت از نظر مايكوبـاكتريوم توبر كلئز يس مثبت بود

نتيجه عيرى: كيس ييش رو يكى از ناشايعترين تظاهرات بيمارى مايكوباكتريوم توبر كوزيس است كه نياز مبرم به بررسى بيمارى مايكوبا كتريوم توبر كلوزيس راد در بيماران مزمن تنفسى و بيماران تنفسى مقاوم به درمان بيان مىدارد. كلمات كليدى: مايكوبا كتريوم توبر كلوزيس، COPD، ينومونى نكروزان

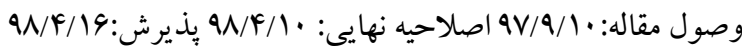


سـى تسى اسـكن ريـه افزايش قطر AP قفسـه سـينه همـراه بـا

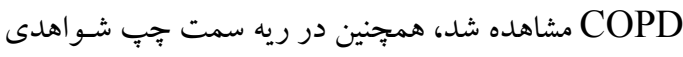

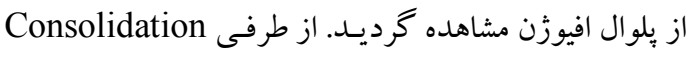

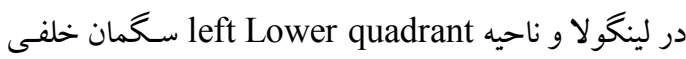

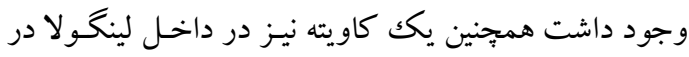

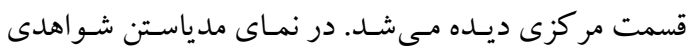
مبنى بر لنفادنوياتى مدياستن وجـود نــدارد.(شـكل r). بيمـار

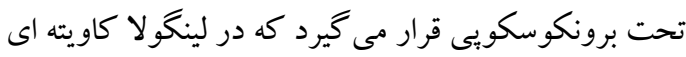
حاوى آنتراكوزيس و ترشحات سياه رنغك مشاهده مى بــوده، همجنين Left upper division بـ دليـل فشـار از خـارج

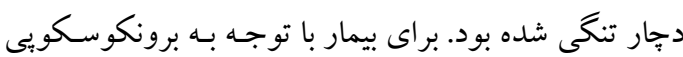

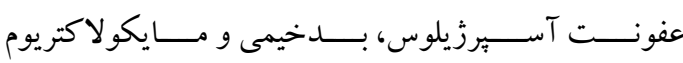

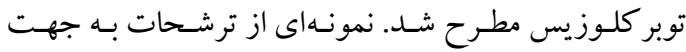

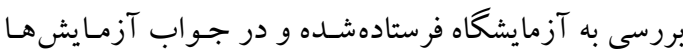

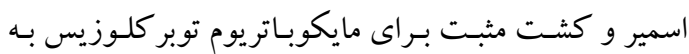

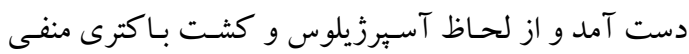

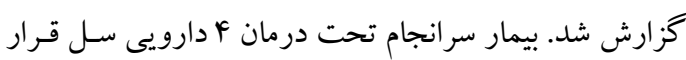

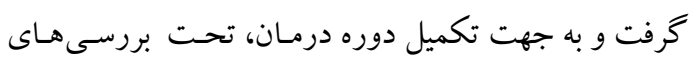
دوره قرار گرفت.
مقدمه ينومونى نكروزان يكى از بيمـارىهـاى ناشـايع ريـوى ولى

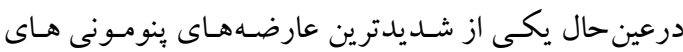

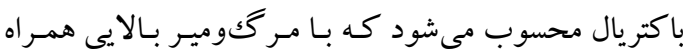

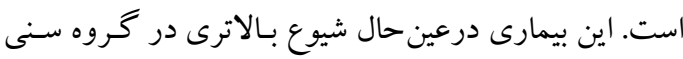
كودكك دارد و عامل استاف اورئوس شيوع بيشترى در بروز

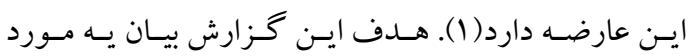

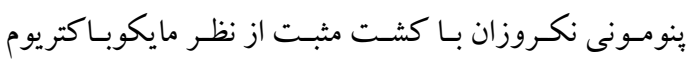
توبر كلوزيس است.

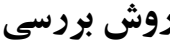

بيمار آقاى سr ساله كيس شناخته شـدهى COPD از جهار

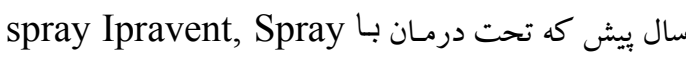
Atrovent, Spray seroflu, Tab. Theophylline, Tab. meunteleukast

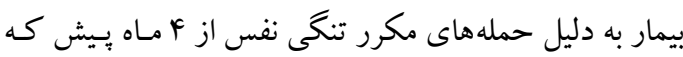

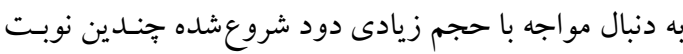

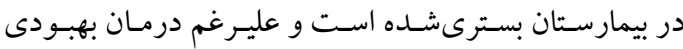
كامل حاصل نشده است. در آخرين نوبت بسترى بـه جهـت

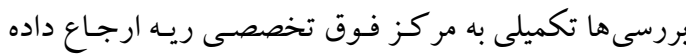

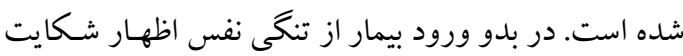
مى كند تنكى نفس در حال استر احت بوده و همـراه بـا سـرفه

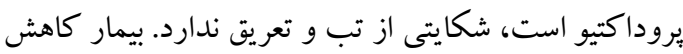

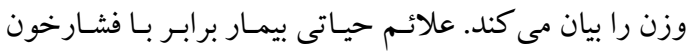

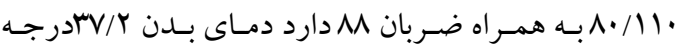

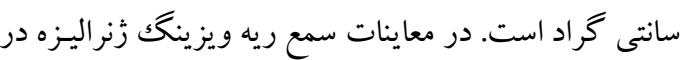
هر دو ريـه شـنيده مسىشـد و كاهش صـداى ريـوى در ريـه

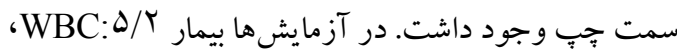
PLT: به همراه تست هـاى انعقـادى نرمال

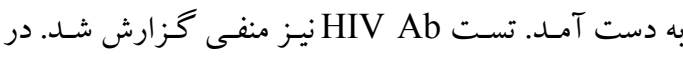
تصـويربردارى در Consolidation :chest X-ray

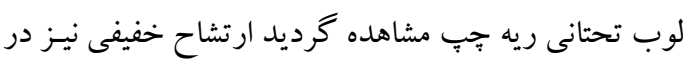

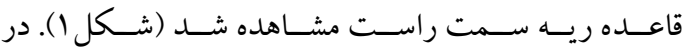

همله علهى دانشكاه علوه بِزشكى كردستان / دوره بيست و يَنمه / آذر و دى 9وسرا 


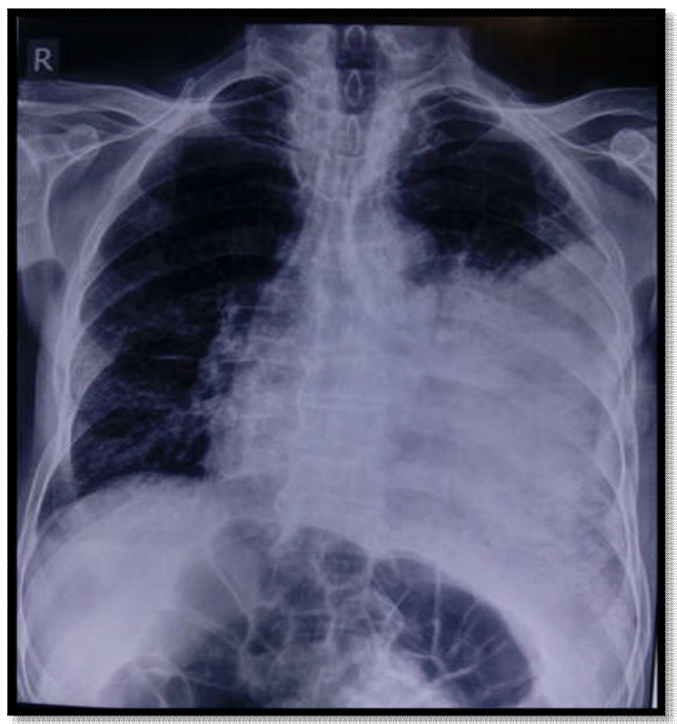

شكل ا. در تصوير راديوكر افى بيمار Consolidation

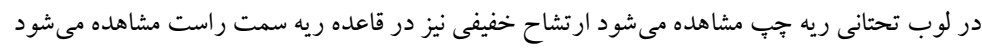
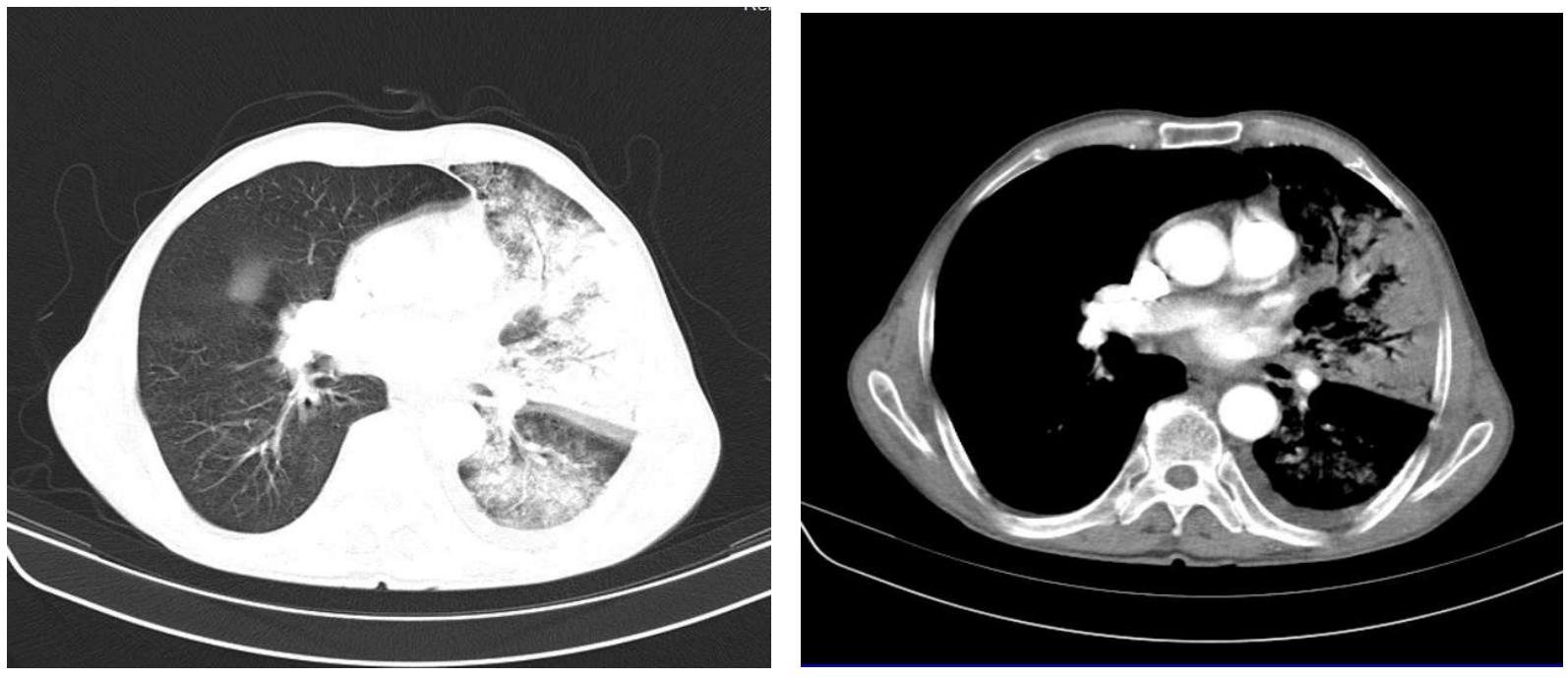

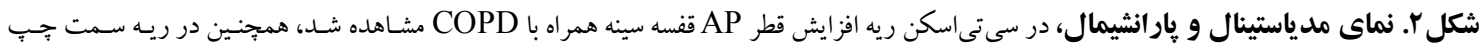
شو اهدى از يلو ال افيوزن مشاهده گرديد. از طرفى Consolidation در لينكو لا و ناحيه

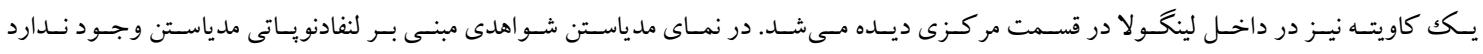


از TB در محل درگيرى، اسكار فيبروتيكك همراه با كلسيفيكاسيون رخ مىدهد. لنفادنوياتى داخل مدياستن

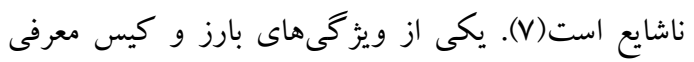

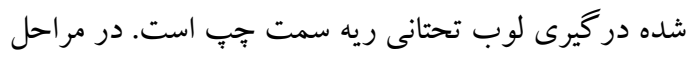
بيشرفت بيمارى به دليل انتقال برونكوزنيك عند عنونت

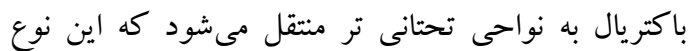

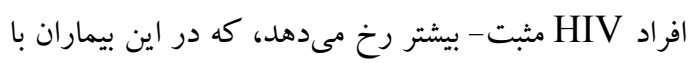

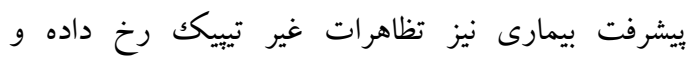

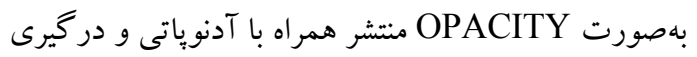
لوب تحتانى خود را نشان مىدهد.

\section{نتيجه كيرى} يكى از ويز گىهاى كيس معرفى شده تظاهرات آتيييك سل در بيمار سالم است كه موجب دشوارى تشخيص

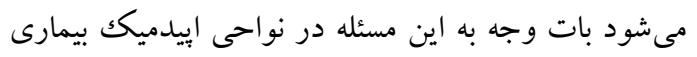

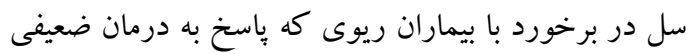
دارند بهتر است بيمارى سل را مورد بررسى قرار گيرد.

$$
\text { تشكر و قدردانى }
$$

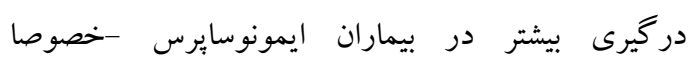

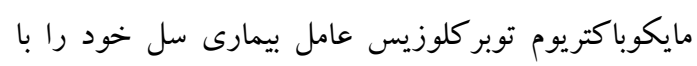

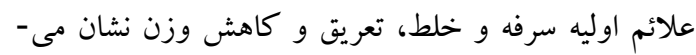

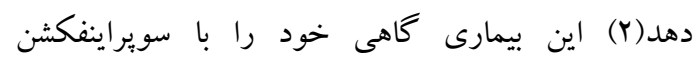

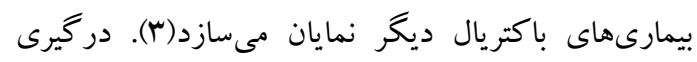

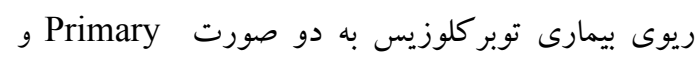

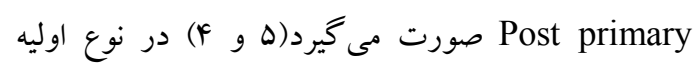
بيمارى بهصورت درگيرى ناف ريه با درگيرى لوبار است

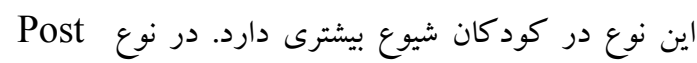
بيمارى با اكتيو شدن سل قبلى بروز مى يابد (9). primary

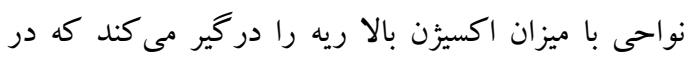

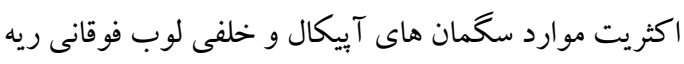

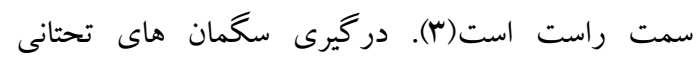

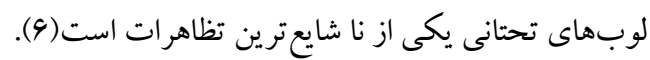

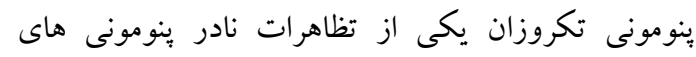

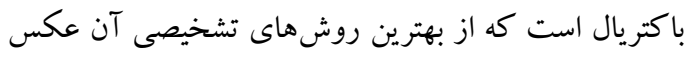

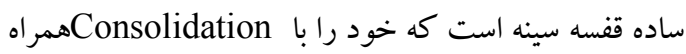
با التهاب اطراف و كاويتى خود را نشان مىدهد(r). هرجند در لا درصد افرادى كه TB مثبت دارند احتمال دارد Chest X-ray

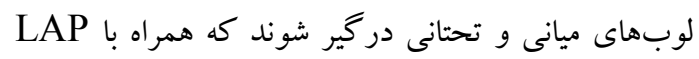

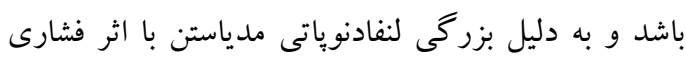

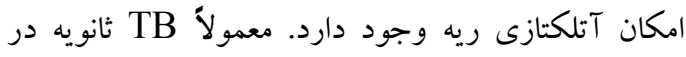
لوبهاى فوقانى يكك يا هردو ريه رخ مىدهد. كاويتاسيون

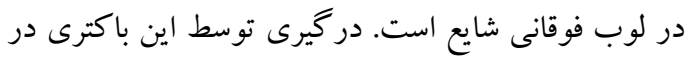
لوب تحتانى و سخمان هاى قدامى شيوع جندانى ندارد. بعد لوند

منابع

1. N. Chatha, et al., "Management of necrotizing pneumonia and pulmonary gangrene: a case series and review of the literature," Can Respir J.2014; 21: 239-45.

2. B. C. de Souza, et al., "Oral manifestation of tuberculosis: a case-report," Braz J Infect Dis. 2016; 20:210-3.

3. Y. F. Tsai and Y. H. Ku, "Necrotizing pneumonia: a rare complication of pneumonia requiring special consideration," Curr Opin Pulm Med. 2012;18: 246-52.

4. O. N. Hatipoglu, et al",.High resolution computed tomographic findings in pulmonary tuberculosis," Thorax.1996;51:397-402.

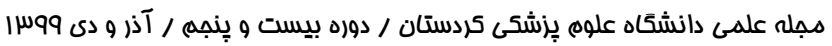


5. K. S. Lee, et al., "Adult-onset pulmonary tuberculosis: findings on chest radiographs and CT scans," AJR Am J Roentgenol.1993;160:753-8.

6. J. Y. Yoon, et al., "CT findings in apical versus basal involvement of pulmonary tuberculosis," Diagn Interv Radiol.2013;19:85-90.

7. V. C. Broaddus, et al., Murray \& Nadel's Textbook of Respiratory Medicine E-Book: Elsevier Health Sciences, 2015. 